\title{
Algumas impressões e sugestões sobre o ensino de história da África
}

Some impressions and suggestions on teaching African history

Marina de Mello e Souza*

\section{Resumo}

Com base na experiência como professora de história da África e no contato com professores de níveis diversos, indico alguns problemas referentes ao ensino de história da África e, secundariamente, cultura afro-brasileira, e proponho formas de o professor abordar o tema e aprimorar seu domínio sobre a área.

Palavras-chave: ensino de história da África; pesquisa de história da África; vencendo preconceitos.

\section{Abstract}

From my experience as a teacher of African history and the contact with teachers working in different levels, I point out some problems concerning teaching African history and, secondarily, afro-Brazilian culture, and I suggest ways that can help teachers to approach the subject and to enhance their knowledge about this area.

Keywords: teaching of African history; researching African history; struggling against prejudices.

Quase dez anos após a promulgação da Lei 10.639, que regulamentou a obrigatoriedade do ensino de história da África e cultura afro-brasileira nas escolas de nível fundamental e médio, o tema ainda é polêmico e a lei não é plenamente aplicada. Como o assunto é dos mais delicados, envolvendo questões centrais na construção da nacionalidade e identidade brasileiras no que diz respeito às formas como as heranças africanas e escravistas deixaram suas marcas, essas dificuldades são compreensíveis. Inserirmos as formas de abordar as contribuições africanas nos processos históricos e nos contextos que as conformaram da maneira como se apresentam hoje é condição para que entendamos melhor como lidamos com elas. E é assim que têm agido os interessados no assunto que o abordam com mais seriedade, considerando as noções

\footnotetext{
* Departamento de História, Faculdade de Filosofia, Letras e Ciências Humanas, Universidade de São Paulo (FFLCH/USP). Av. Prof. Lineu Prestes, 338. 05508-000 - São Paulo - SP - Brasil. marinamsouza@usp.br
} 
evolucionistas e da ideologia do branqueamento em vigor no final do século XIX e início do XX, os conflitos e contradições presentes na consolidação de uma jovem nação que buscava se integrar no mundo ocidental de acordo com os valores dele emanados, as soluções encontradas por intelectuais e políticos para afirmar uma identidade própria, mestiça, agregadora e inimiga de conflitos abertos, e as várias maneiras, em diferentes momentos, pelas quais militantes negros propuseram que a segregação racial fosse tratada, em termos não só teóricos mas também práticos.

O meu ingresso no terreno do ensino de história da África e cultura afro-brasileira deu-se a partir do momento em que me tornei professora de história da África, em 2001, e principalmente depois de ter escrito um livro paradidático, África e Brasil africano, cuja primeira edição é de 2006, portanto derivado da minha prática e não de um projeto prévio. Desde então criamos um novo curso no Departamento de História da Universidade de São Paulo (USP), voltado para ajudar futuros professores a cumprirem as demandas da Lei 10.639, e passei a dar palestras e visitar escolas em vários lugares do Brasil para apresentar o livro e conversar com professores sobre o ensino dos temas ali contidos. Essas experiências, ligadas à academia e ao ensino fundamental e médio, permitiram-me conhecer ações e situações diversas.

É nítido que nos últimos anos, a despeito das dificuldades e, em muitos casos, da falta de empenho daqueles que deveriam estar à frente dos processos de implantação da lei, os temas ligados à cultura afro-brasileira e à África ganharam espaço nas reflexões e ações dos educadores. Isso pode ser constatado pela proliferação dos cursos de formação de professores voltados para o assunto, por meio da produção de material didático, elaboração de sites e publicação de literatura infanto-juvenil e adulta. O que não quer dizer que estejamos em céu de brigadeiro, pois parte do material didático apresenta problemas significativos quanto à forma como os temas são apresentados, muitas vezes reforçando estereótipos e frequentemente demonstrando um conhecimento muito precário no que diz respeito à história da África. Com relação aos cursos de formação tenho menos conhecimento. Esse quadro é resultado de anos de desatenção aliada à súbita valorização do assunto e às demandas não só educacionais como também de mercado, mas pode ser alterado de forma positiva com o tempo e atitudes adequadas. 
Olhando para minha própria experiência, entendo que o mais importante para avançarmos de forma adequada no sentido de produzir e transmitir um conhecimento de qualidade é trazermos para primeiro plano a necessidade de estudo e pesquisa. Sem eles, não há como alcançar e transmitir conhecimentos de qualidade. Se esses requisitos são mais fáceis de alcançar quando estamos inseridos no meio universitário (e mesmo nele, nem sempre), eles devem ser estendidos para todos os níveis da educação, pois sem formação adequada e tempo para estudo permanente fica difícil ser um professor dinâmico, atualizado, com capacidade não só de transmitir informações corretas como de captar a atenção dos alunos, num mundo cada vez mais cheio de estímulos interessantes e absorventes. E se já é difícil manter-se atualizado com relação a temas há muito explorados, a dificuldade aumenta quanto tratamos de assuntos estigmatizados, permeados de preconceitos e, por isso mesmo, postos à margem.

No que diz respeito ao ensino de história, as universidades são a principal instância formadora de professores e há nelas um aumento da atenção dada à África que pode ser medido pelo número de concursos que são abertos nessa área. Entretanto, mesmo nesse âmbito, que podemos considerar pioneiro, percebemos a dificuldade no estabelecimento de estudos africanos, seja por estarem frequentemente diluídos nos estudos sobre tráfico e escravidão, seja pela dificuldade em preencher os postos abertos, na medida em que muitos concursos não aprovam nenhum candidato. Passando para o ensino fundamental e médio, ao lado das exceções representadas por experiências bem-sucedidas, multiplicam-se os depoimentos de professores que, para atender à lei ou por interesse particular, propõem medidas às coordenações das escolas nas quais dão aulas, sem serem ouvidos. As ações tomadas nesse sentido ficam, então, geralmente restritas às iniciativas pontuais e individuais, que além de não terem apoio institucional muitas vezes são mal vistas pelos colegas e superiores. Em tese defendida no Departamento de Antropologia da USP, Raquel Bakke chamou de "pedagogia do evento" uma situação também recorrente, na qual são desenvolvidas atividades relacionadas a datas específicas como o Dia da Consciência Negra ou celebrações em torno do dia 13 de maio, sem nenhum desdobramento posterior. ${ }^{1}$

Há ainda a situação na qual são tomadas iniciativas no sentido de promover estudos sobre a África e a cultura afro-brasileira, mas o despreparo ou os 
interesses políticos dos agentes levam a que o enfoque adotado e os conteúdos transmitidos careçam de consistência ou mesmo veiculem informações erradas. Nesse sentido, não é raro encontrarmos material didático, tanto para suporte de cursos de formação quanto para ser usado em aula, cheio de erros grosseiros, principalmente quanto se trata de história da África, ou de partidarismos ideológicos resultantes de uma dada militância, principalmente quando aborda temas relativos à cultura afro-brasileira. A despeito desses problemas, característicos de uma área em processo de constituição e permeada de questões ideológicas, não se pode jogar a criança fora com a água do banho. O importante é que os problemas sejam detectados com acuidade cada vez maior e os desvios sejam corrigidos: e pelo que percebo isso vem sendo feito com o aprimoramento e a disseminação do conhecimento sobre assuntos africanos e o desnudamento dos preconceitos que envolvem o tratamento de temas afro-brasileiros.

O aprimoramento do conhecimento acerca da história da África pode ser medido pelo aumento de traduções para o português de textos importantes para a área e da publicação de trabalhos produzidos por estudiosos brasileiros, na maior parte das vezes vinculados a programas de pós-graduação. ${ }^{2}$ A disseminação desse conhecimento produzido na esfera acadêmica deve ser alcançada com a sua articulação com outros níveis de ensino, revistas de divulgação, programas ligados a mídias audiovisuais, cursos de curta duração e outras formas de levar para fora dos limites da universidade o conhecimento ali produzido. Na medida em que essa articulação ganhe força, será possível garantir um ensino de qualidade com menos margem de erro, tanto no que diz respeito à produção de material didático quanto no que se refere às aulas nos diversos níveis e cursos de formação de professores. E pelo que vemos, esse processo está em curso, mesmo que com menor velocidade e abrangência do que seria ideal.

Quando nos voltamos para os segmentos menos favorecidos, que frequentam as escolas públicas, nas quais as condições de trabalho são na maior parte das vezes bastante precárias, há uma variável importante que, conforme vários relatos, tem prejudicado a implantação do estudo de temas africanos e afro-brasileiros. Ela diz respeito à resistência, e mesmo oposição aberta, dos adeptos de religiões evangélicas quanto ao ensino de cultura afro-brasileira. São vários os depoimentos relativos à dificuldade de abordar assuntos relativos à 
religiosidade africana ou afro-brasileira na presença desses grupos, os quais se recusam a tratar do assunto, quando não partem para a ofensiva diante do que entendem serem seitas diabólicas.

Esse tema foi abordado com vagar na já mencionada tese de Raquel Bakke. Por meio de uma pesquisa de campo a autora constatou que a esfera religiosa é a preferencialmente eleita pelos professores e programas de cursos para abordar a cultura afro-brasileira. De acordo com sua análise há um processo de transformação da religião em cultura, com aquela assumindo a totalidade da expressão desta. Isso estaria ligado à elevação do candomblé como símbolo máximo da identidade afro-brasileira e à sua associação com a ideia de resistência negra na construção de identidades. Como o ensino de temas afro-brasileiros estaria intimamente vinculado a uma posição política, a religião, como espaço maior de resistência, seria privilegiada como tema. Dessa forma, aumentaria a dificuldade da implantação real da Lei 10.639, pois são justamente os temas ligados às religiosidades afro-brasileiras os que encontram maior resistência junto a professores e alunos, principalmente se a presença de evangélicos for significativa. Esse mecanismo recorrente seria, no seu entender, um fator, entre outros, da dificuldade de execução das recomendações da lei. Diante do quadro descrito pela autora, me parece que um caminho para contornar essa dificuldade seria mudar o foco de interesse principal para outra esfera, que não a religiosa, e dessa forma introduzir conhecimentos que permitissem a construção de uma relação respeitosa com a alteridade representada pela cultura afro-brasileira.

Vale notar que a pesquisadora estava preocupada com o ensino de cultura afro-brasileira e não de história da África, sugerindo ser exagerada a preocupação com o esta última ao dizer que,

Se é possível fazer a crítica ao conteúdo de história, que insiste em dar mais ênfase à história da África, e continua não abrindo muito espaço para se analisar o papel do negro como sujeito político após a abolição da escravidão, as demais disciplinas, como geografia, sociologia e filosofia, possibilitam essa abordagem. ${ }^{3}$

É fato que ao fazer essa observação a autora está apontando para a deficiência no tratamento do negro como agente histórico, mas atribui isso à atenção excessiva dada à história da África. No meu entender, o que acontece é justamente o contrário. Uma vez que os professores pouco sabem acerca das 
sociedades africanas, seus sistemas de pensamento e os processos históricos por elas vividos, têm dificuldade em abordar temas carregados de preconceitos de forma a derrubá-los, ao tratar os fenômenos das culturas afro-brasileiras com base nas lógicas de suas matrizes africanas e dos processos que lhes deram origem. Minha posição é de que somente conhecendo bem as sociedades africanas, suas histórias e os processos que nos ligam a elas, assim como desvendando as noções por trás da construção histórica e ideológica dos preconceitos contra o africano e o negro, teremos condições de analisar com consistência as manifestações afro-brasileiras e o lugar que os africanos e seus descendentes ocuparam no passado e ocupam no presente, no contexto da sociedade brasileira como um todo.

Dessa forma, minha perspectiva também é bastante diferente da que me parece ser a do movimento negro em geral, que vê a lei como possibilidade de afirmação política e inclusão social de um segmento marginalizado da população. Não que eu discorde disso, mas penso que não são as razões políticas que devem indicar o caminho, sendo o alcance de suas bandeiras o ponto de chegada, e não o de partida. As boas intenções daqueles que se guiam principalmente pelas razões políticas acabam sendo fragilizadas pelo descaso quanto à necessidade de abordar os temas de forma consistente, resultante de estudo e conhecimento aprofundado acerca deles. Informações equivocadas, e mesmo perniciosas, podem acabar por comprometer as boas intenções, dando munição aos que não concordam com a existência da lei e argumentam que ela reflete uma postura autoritária ou mesmo que acirra antagonismos fundados em distinções de base racial. Postura com a qual não concordo de forma alguma e que desconsidera a longa luta encabeçada pelo movimento social genericamente chamado de movimento negro, que conquistou, vencendo resistências profundamente arraigadas na sociedade brasileira, um importante espaço no caminho da construção de uma sociedade mais igualitária, na qual as diferenças de aparência e ancestralidade não possam ser acionadas como instrumentos para inferiorizar e marginalizar alguns segmentos sociais.

Como Raquel constatou em sua pesquisa, os temas ligados às culturas afro-brasileiras são assuntos que incomodam, o que resulta na dificuldade em colocar em prática a lei. Para que os temas deixem de incomodar é necessário, no meu entender, explicitar os processos históricos e ideológicos presentes nas bases das percepções contemporâneas acerca da África e da cultura afro-bra- 
sileira, como aliás, conforme dito no início deste texto, é indicado por várias pessoas que se detiveram sobre o assunto. Dessa perspectiva, é fundamental o ensino de temas africanos, considerados não apenas pelos seus aspectos negativos, largamente divulgados pela imprensa e pelas mídias oficiais, mas sim pelo que podemos chamar de aspectos positivos, ou seja, as características culturais e formas de organização social e política próprias, os processos históricos tanto internos quanto pertinentes à sua relação com outros continentes, seja com as sociedades ocidentais, seja com as orientais.

No meu entender, ao tratarmos de assuntos africanos em geral e história da África em particular, devemos partir do princípio de que temos pouca, ou mesmo nenhuma familiaridade com os temas relativos ao continente africano. Dessa forma, como já dito, o estudo e a pesquisa são requisitos fundamentais para adquirirmos essa familiaridade e aprofundar o conhecimento sobre a África. Se olharmos para a trajetória da construção desse conhecimento no âmbito do chamado mundo ocidental, do qual fazemos parte, veremos que os europeus só passaram a conhecer melhor o continente africano na segunda metade do século XIX, quando se multiplicaram as expedições de exploração. Naquele momento, além de o combate às doenças ali existentes ter se tornado mais eficiente, permitindo a maior sobrevivência dos estrangeiros, as técnicas de medição e de transporte estavam aprimoradas, o que contribuiu para a elaboração de um conhecimento mais preciso sobre o interior da África. Nesse processo são importantes as sociedades de geografia e as companhias de comércio interessadas em atuar nos espaços africanos, principalmente comprando matérias-primas e explorando suas riquezas naturais.

Outro princípio fundamental do qual devemos partir diz respeito aos preconceitos associados aos povos africanos e suas sociedades. Quando o conhecimento sobre o continente começou a se aprofundar, predominavam as ideias de hierarquia entre as raças, baseada em diferenças biológicas, e de hierarquia entre as sociedades, fundada em níveis de evolução. Nesse contexto a África era vista como um continente atrasado, primitivo, habitado por populações em estágios inferiores da evolução humana. Havia variações nessa classificação, e no Brasil, no final do século XIX e ao longo do XX, os iorubás eram vistos como superiores aos bantos, percebidos como detentores de culturas menos complexas, portanto mais primitivas. Essa postura deve ser entendida como resultado de uma maneira de pensar historicamente constituída, ligada a de- 
terminadas teorias que se tornaram ultrapassadas por maneiras de pensar que vieram depois e negaram a ideia de hierarquia entre as raças e mesmo entre as culturas, noção que substituiu a de raças. Hoje pensamos em termos de diferenças culturais, de sistemas simbólicos, sem inserir as diferenças em uma escala evolutiva, associada às ciências biológicas. Na era da valorização do multiculturalismo e das diferenças os preconceitos podem ser superados ao mostrarmos as bases sobre as quais eles foram construídos, e que não se sustentam mais.

No caso específico da história, outro ponto de partida para abordar o continente africano é descartar a ideia de que documentos escritos são imprescindíveis para o conhecimento histórico. Essa também é uma visão ultrapassada na medida em que a história contemporânea incluiu em sua esfera de interesse as camadas populares e mesmo iletradas, sendo suas preocupações antes centradas nos feitos dos dirigentes e dos heróis. Paralelamente a isso, a história passou a utilizar instrumentos de outras disciplinas como a antropologia, a análise literária, a geografia, a arqueologia e a linguística, assim como passou a considerar a oralidade uma fonte produtora de informações importantes para a reconstrução dos acontecimentos e processos históricos. Essa postura permite que seja aceita a possibilidade de fazer a história de populações que não deixaram registros escritos e cuja importância não é medida pelo impacto de suas ações na história da humanidade como um todo.

Considero central no ensino de história da África a identificação destes três pontos de ordem mais geral: o desconhecimento sobre o continente africano, a desconstrução dos preconceitos a ele relacionados e a multiplicidade de possibilidades metodológicas na construção do conhecimento histórico. Quanto a o que ensinar, à guisa de auxiliar o professor nesse campo ainda pouco percorrido, proponho alguns conjuntos de fontes para buscar informações sobre a África, considerando a divisão cronológica tradicional no campo da história, assim como o recurso aos documentos escritos, sem me deter nas diferentes escolas de interpretação, pois há uma variedade delas a orientar as análises dos processos ali ocorridos nos diversos tempos. ${ }^{4}$

Com relação ao período chamado de Antiguidade pela historiografia, as regiões com maior quantidade de informações são as próximas ao rio Nilo, ao mar Vermelho e ao Mediterrâneo, que estavam inseridas nos circuitos comerciais e políticos em curso naquela região, considerada em sua totalidade. Fon- 
tes gregas, romanas e árabes trazem indícios sobre acontecimentos e processos ocorridos no Egito, na Núbia, na Etiópia, nos portos do mar Vermelho e do Mediterrâneo.

Com relação ao período chamado de Idade Média pela historiografia, além de relatos sobre as regiões acima mencionadas existem ainda fontes sobre as sociedades existentes às bordas leste e sul do deserto do Saara, como Gana, Mali e Songai, principalmente de comerciantes e viajantes árabes. Para o final desse período e já entrando na Idade Moderna, existem relatos feitos por africanos islamizados, que incorporaram a escrita a partir do contato com os árabes na região do Sael, sendo os exemplos mais conhecidos as crônicas escritas no século XVII: Ta'rikh al-Sudan e Ta'rikh el-Fattash, traduzidas para o francês no início do século XX.

Com relação ao período chamado de Idade Moderna pela historiografia, além da existência de documentos sobre todas as regiões já mencionadas, a presença de europeus nas costas atlântica e índica do continente produziu um aumento considerável de relatos escritos por estrangeiros, como comerciantes, administradores, missionários católicos e viajantes. O contato com os europeus em alguns lugares também levou à incorporação da escrita, havendo documentos escritos produzidos por africanos principalmente em regiões da África centro-ocidental. ${ }^{5}$

Com relação ao período chamado de Contemporâneo, os documentos escritos são ainda mais abundantes, acompanhando os processos de incorporação dos padrões ocidentais por parte das sociedades africanas, intensificados a partir do final do século XIX e da ocupação colonial por grande parte do continente, e mais ainda a partir das independências nacionais. Além dos textos produzidos pelas viagens de exploração e pelas relações comerciais e diplomáticas, foram escritos muitos trabalhos sobre as sociedades africanas, abordadas principalmente a partir de suas organizações políticas e sociais, mas também de seus processos históricos, mesmo que em menor quantidade. Se num primeiro momento predominaram os trabalhos feitos pelos agentes coloniais e as perspectivas próprias dos lugares que eles ocupavam, a partir dos anos 1960, das independências nacionais e da consolidação de centros de estudo e pesquisa acadêmica, africanos passaram a escrever sua história combinando perspectivas ocidentais com as tradicionais, ganhando destaque o recurso à história oral. 
Quanto às fontes não escritas, além da oralidade, considerada como forma de acesso ao passado desde os gregos, disciplinas como a arqueologia, a linguística, a geografia, a antropologia e a análise literária contribuem para um maior conhecimento acerca do continente africano e de sua história. Aqui vale chamar a atenção para a especificidade do que estamos chamando de história, ou seja, uma disciplina formada no âmbito das formas de conhecimento ocidentais, que lida com a ação dos homens ao longo do tempo. Esta é uma maneira específica de apreensão do passado, que segue procedimentos e regras próprias, existindo outras possibilidades de lidar com o passado das sociedades, como as eminentemente africanas. Nestas a transmissão oral das informações, que podem ser de diferentes naturezas (genealogias, lendas, mitos, história das migrações, saberes técnicos), caracteriza maneiras específicas de lidar com o conhecimento sobre o passado e a sua transmissão. ${ }^{6}$

Para fazer história da África hoje no Brasil, não dispomos de muitos materiais, mas, com a proliferação de textos digitalizados e a publicação de fontes, é possível fazer alguma coisa. O aprofundamento do conhecimento exige o domínio de pelo menos uma língua estrangeira (inglês ou francês), na medida em que ainda há muito poucas traduções de trabalhos de história, publicados na forma de livros ou de artigos em revistas especializadas. A ampliação do número de títulos disponíveis em bibliotecas, as assinaturas de revistas e o enriquecimento de acervos, de obras escritas ou da chamada cultura material, são tarefas que devem ser priorizadas pelas instituições de ensino e pesquisa para que os estudos africanistas se consolidem entre nós. $\mathrm{E}$ isso vem acontecendo não apenas no âmbito do ensino superior, em várias universidades do país, como também em museus e instituições de pesquisa que, como dito, devem estreitar cada vez mais seus laços com o ensino básico e fundamental, de forma a consolidar o ensino e a pesquisa sobre assuntos africanos em terras brasileiras. $^{7}$

Como tudo que diz respeito ao conhecimento e ao ensino, o estudo é fator indispensável para o professor atingir plenamente seus propósitos de educador, e, além da motivação individual, é preciso haver apoio institucional para isso, tanto na forma de tempo disponível como na de remuneração adequada que considere o trabalho feito fora da sala de aula. Sendo a interferência nestes últimos fatores tarefa de segmentos organizados em termos políticos e traba- 
lhistas, fica aqui a minha modesta contribuição no que diz respeito às possibilidades de aprimoramento individual.

\section{NOTAS}

${ }^{1}$ BAKKE, Raquel Rua Baptista. Na escola com os orixás: o ensino das religiões afro-brasileiras na aplicação da Lei 10.639. Tese (Doutorado) - Programa de Pós-Graduação em Antropologia Social, Departamento de Antropologia, FFLCH, USP. São Paulo, 2011. p.88.

${ }^{2}$ Dentre as traduções mais recentes destaco os oito volumes da História Geral da África disponíveis em www.unesco.org/new/pt/brasilia/about-this-office/single-view/news/general_history_of_africa_collection_in_portuguese-1/; M'BOKOLO, Elikia. África negra. História e civilizações. Trad. Alfredo Margarido. Salvador: Ed. UFBA; São Paulo: Casa das Áfricas, 2009; THORNTON, John. A África e os africanos na formação do mundo atlântico, 1400-1800. Trad. Marisa Rocha Motta. Rio de Janeiro: Campus; Elsevier, 2004; LOVEJOY, Paul E. A escravidão na África: uma história de suas transformações. Trad. Regina A. R. F. Bhering e Luiz Guilherme B. Chaves. Rio de Janeiro: Civilização Brasileira, 2002. Dentre os autores nacionais, destaca-se SILVA, Alberto da Costa e, autor de, entre outros, A enxada e a lança: a África antes dos portugueses. Rio de Janeiro: Nova Fronteira; São Paulo: Edusp, 1992; A manilha e o libambo: a África e a escravidão de 1500 a 1700. Rio de Janeiro: Nova Fronteira; Fundação Biblioteca Nacional, 2002; Um rio chamado atlântico: a África no Brasil e o Brasil na África. Rio de Janeiro: Nova Fronteira; Ed. UFRJ, 2003; Francisco Félix de Souza, mercador de escravos. Rio de Janeiro: Nova Fronteira; Ed. Uerj, 2004. Quanto a trabalhos produzidos no âmbito dos programas de pós-graduação, foram publicados alguns produzidos no Departamento de História da USP, como: GEBARA, Alexsander. A África de Richard Francis Burton: antropologia, política e livre-comércio, 1861, 1865. São Paulo: Alameda, 2010; SANTOS, Gabriela Aparecida dos. Reino de Gaza: o desafio português na ocupação do sul de Moçambique (1821-1897). São Paulo: Alameda, 2010; SILVA, Juliana Ribeiro da. Homens de ferro: os ferreiros da África central no século XIX. São Paulo: Alameda, 2011.

${ }^{3}$ BAKKE, Raquel Ruas Batista, op. cit., p.74-75.

${ }^{4}$ Para referências de narrativas de diversos momentos e procedências, ver FAGE, J. D. A evolução da historiografia da África. História Geral da África I, p.1-22. Disponível em: www.dominiopublico.gov.br/download/texto/ue000318.pdf.

${ }^{5}$ SANTOS, Catarina Madeira; TAVARES, Ana Paula. Africae Monumenta, v.I. Arquivo Caculo Cacahenda. Lisboa: Centro de Estudos de História e Cartografia Antiga/ Instituto de Investigação Científica Tropical, 2002, apresenta um conjunto de textos que exemplificam a apropriação da escrita por sociedades centro-africanas antes do século XIX.

${ }^{6}$ Um texto clássico sobre a questão da oralidade e da memória nas sociedades africanas é HAMPATÉ BÂ, Amadou. A tradição viva. In: KI-ZERBO, Joseph (Org.) História Geral da África I. Metodologia e pré-história da África. São Paulo: Ática; Unesco, 1980. Também 
disponível em: unesdoc.unesco.org/images/0019/001902/190249por.pdf. Quanto a uma perspectiva acadêmica o livro que primeiro se debruçou sobre o tema é VANSINA, Jan. Oral tradition as History. Madison: The University of Wisconsin Press, 1985.

${ }^{7}$ Em São Paulo vale destacar a atuação educativa do Museu Afro-Brasil, que recebe grande quantidade de escolas, tem uma bem treinada equipe de educadores e uma importante biblioteca.

Artigo recebido em 20 de janeiro de 2012. Aprovado em 26 de março de 2012. 